\title{
Photorefractive recording in $\mathrm{LiNbO}_{3}: \mathrm{Mn}$
}

\author{
Yunping Yang \\ Department of Electrical Engineering, California Institute of Technology, Pasadena, California 91125
}

Karsten Buse

Physikalisches Institut, Universität Bonn, Wegelerstrasse 8, D-53115 Bonn, Germany

Demetri Psaltis

Department of Electrical Engineering, California Institue of Technology, Pasadena, California 91125

Received October 3, 2001

The dynamic range, sensitivity, and dark decay of holographic recording of wavelength $458 \mathrm{~nm}$ in $\mathrm{LiNbO}_{3}$ crystals doped with 0.2 -at. \% Mn with different oxidation states have been measured. The measured sensitivity is $0.5 \mathrm{~cm} / \mathrm{J}$ and is found to be independent of the oxidation state, and the largest $M / \#$ obtained is $12 / \mathrm{mm}$ (extraordinary light polarization; light wavelength, $458 \mathrm{~nm}$ ). This combination of very large $M / \#$ and high sensitivity is in strong contrast with results for $\mathrm{LiNbO}_{3}: \mathrm{Fe}$ for which a direct trade-off exists between $M / \#$ and sensitivity. The activation energy of the dark decay of holograms stored in these $\mathrm{LiNbO}_{3}: \mathrm{Mn}$ crystals is $\sim 1.0 \mathrm{eV}$, which is characteristic of proton compensation and leads to a projected lifetime of holograms of three years at room temperature. (c) 2002 Optical Society of America

OCIS codes: $090.2900,090.7330,160.3730,210.0210,210.4810$.

Photorefractive $\mathrm{LiNbO}_{3}$ crystals have been of intense interest for applications such as holographic data storage $^{1}$ and narrow-band wavelength filters for optical telecommunications. ${ }^{2-4}$ Two of the most important properties of $\mathrm{LiNbO}_{3}$ crystals are dopant and doping level. Usually, transition-metal dopants, such as Fe, $\mathrm{Cu}, \mathrm{Ce}$, and $\mathrm{Mn}$, are added to the melt as oxides to improve the photorefractive effect. Among all kinds of dopants, $\mathrm{Fe}$ has been investigated extensively, whereas Mn has been less popular and its role in $\mathrm{LiNbO}_{3}$ is not understood completely. It is known that in $\mathrm{LiNbO}_{3}$ crystals the $\mathrm{Mn}$ center is deeper than the Fe center, and doubly doped $\mathrm{LiNbO}_{3}: \mathrm{Fe}: \mathrm{Mn}$ crystals have been used to achieve nonvolatile holographic storage. $^{5}$

We performed holographic experiments with a $\mathrm{LiNbO}_{3}$ crystal doped with 0.2 -at. \% Mn, with dimensions of $1.0 \mathrm{~mm} \times 4.0 \mathrm{~mm} \times 4.5 \mathrm{~mm}$. The $c$ axis of the crystal is parallel to its longest direction. The crystal was proton reduced by annealing treatment. In our experiments, in which we measured $M / \#$ (Ref. 6) and sensitivity, an argon-ion laser beam with wavelength $458 \mathrm{~nm}$ was used to record and erase holograms. The crystal was placed on a rotation stage. The laser beam was split into two equal-intensity extraordinarily polarized beams that were expanded to cover the whole crystal during recording and erasure. The intensity of each beam was $\sim 10 \mathrm{~mW} / \mathrm{cm}^{2}$, and the grating vector was aligned along the $c$ axis with a period of $1.1 \mu \mathrm{m}$. During recording, we blocked one beam from time to time to measure the holographic diffraction efficiency. We used Bragg-mismatched erasure; i.e., during erasure the sample was rotated away from the Bragg-matched position and illuminated by the same two beams that were used to record holograms. To avoid building another strong hologram, we rotated the sample $0.02^{\circ}$ every $10 \mathrm{~s}$ during erasure. At the end of each period of erasure, we measured the diffraction efficiency by scanning over some range of angles that covered the Bragg-matched position with only the reference beam on. A typical recording and erasure curve for one of the $\mathrm{Mn}$-doped crystals is shown in Fig. 1. From single-hologram recording and erasure, we obtain a sensitivity of $\sim 0.5 \mathrm{~cm} / \mathrm{J}$ and $M / \#$ of $6.5 / \mathrm{mm}$. Here the sensitivity is defined as $S=\left(\mathrm{d} \sqrt{\eta} /\left.\mathrm{d} t\right|_{t=0}\right) /(I L)$, and $M / \#$ is defined as $M / \#=\left(\mathrm{d} \sqrt{\eta} /\left.\mathrm{d} t\right|_{t=0}\right) \tau_{e}$, where $\eta$ is the diffraction efficiency calculated as $I_{\text {diffracted }} / I_{\text {incident }}, L$ is the thickness of the crystal, $I$ is the total intensity of the recording beams, and $\tau_{e}$ is the erasure-time constant.

To verify that such a high $M / \#$ is achievable for practical applications, we multiplexed 100 holograms (extraordinary light polarization; light wavelength,

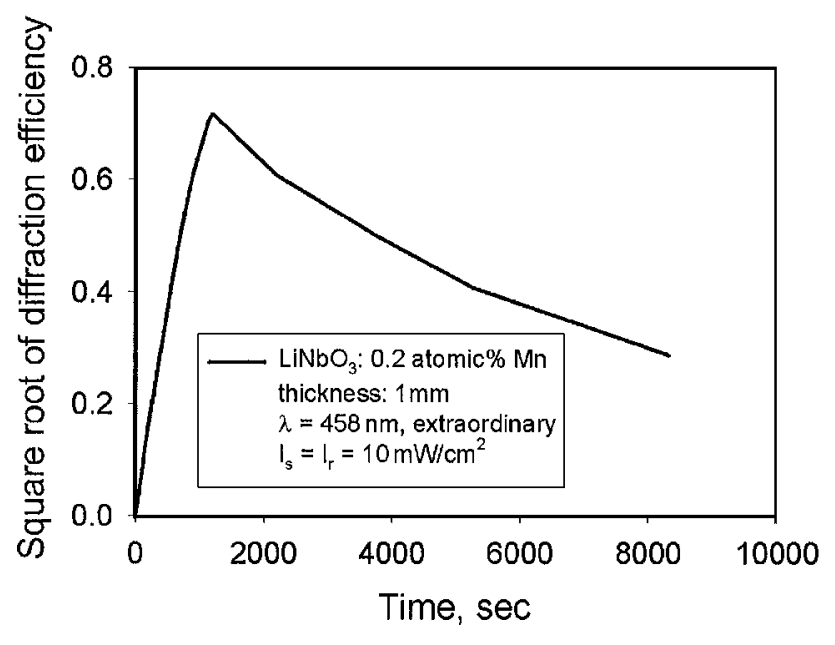

Fig. 1. Typical recording and erasure curve for 1-mm-thick $\mathrm{LiNbO}_{3}: 0.2$-at.\% $\mathrm{Mn}$. 
$458 \mathrm{~nm}$ ). Figure 2 shows the comb function of the 100 multiplexed holograms. We used a precalculated exposure schedule to equalize the diffraction efficiency. The angle between two neighboring holograms is $0.4^{\circ}$. The $M / \#$ obtained from this multiplexing, which was calculated with $M / \#=\sum_{n=1}^{100} \sqrt{\eta_{n}}$, is $5.0 / \mathrm{mm}$, where $\eta_{n}$ is the diffraction efficiency of the $n$th hologram. The loss of some $M / \#$ is due to the nonideal exposure schedule. ${ }^{6}$ The larger diffraction efficiencies around the center of the comb function are due to some backreflection. The $M /$ \#'s obtained from single-hologram recording and multiplexing agree well.

One can change the oxidation state of $\mathrm{LiNbO}_{3}$ crystals by annealing at an elevated temperature in the appropriate atmosphere, typically oxygen for oxidation and argon for reduction. Typically, $M / \#$ and sensitivity are strong functions of the oxidation state. We measured the $M$ /\# and the sensitivity of the Mn-doped crystal with different oxidation states. Table 1 contains information about the thermal treatment for each oxidation state. Since the absorption band of the Mn center is very wide, it is hard to determine the ratio of $C_{\mathrm{Mn}^{2+}} / C_{\mathrm{Mn}^{3+}}$ quantitatively. The measured $M / \#$ and sensitivities for different oxidation states are shown in Fig. 3. The sensitivity is $0.5 \mathrm{~cm} / \mathrm{J}$ and is almost independent of the oxidation state, whereas the $M / \#$ drops by a factor of 15 from the highly oxidized to the highly reduced state. This independence of sensitivity from the oxidation state the $\mathrm{LiNbO}_{3}: \mathrm{Mn}$ is in strong contrast with $\mathrm{LiNbO}_{3}: \mathrm{Fe}$ and is good for holographic applications. The highest $M / \#(12 / \mathrm{mm})$ was obtained for the highly oxidized state.

We measured the dark decay by placing the crystals on a heatable plate whose temperature was controlled to within $0.1^{\circ} \mathrm{C}$ accuracy. An argon-ion laser beam with wavelength $514 \mathrm{~nm}$ was used to record holograms. We performed the dark decay experiments with the Mn-doped crystal described above and also with an Fe-doped crystal (0.25-wt.\% $\mathrm{Fe}_{2} \mathrm{O}_{3}$ ) for comparison. The laser beam was split into two equal-intensity extraordinarily polarized beams that were expanded to cover the whole crystal during recording. Recorded holograms had a grating period of $1.3 \mu \mathrm{m}$ and were written with the grating vector oriented along the $c$ axis. Recording was performed at room temperature. Afterward, the crystals were heated to a certain temperature in the dark, and a weak laser beam of $514 \mathrm{~nm}$ was used to monitor the holographic diffraction efficiency. The weak readout light illuminated the crystal only from time to time, and the intervals between two measurements were long enough to keep the erasure of the holograms by the probing beam negligible. After each experiment the crystal was heated to $230{ }^{\circ} \mathrm{C}$ and kept at this temperature under uniform illumination for $\sim 45 \mathrm{~min}$ to erase the gratings completely. The results are shown in Fig. 4. One can see that the dark decay time constants in both samples, the $\mathrm{Mn}$ - and the Fe-doped crystals, obey an Arrhenius-type dependence on the absolute temperature, $T$, but with two different activation energies, 1.0 and $0.28 \mathrm{eV}$. The different activation energies explicitly indicate two distinct dominant dark decay mechanisms, which have been identified as proton compensation ${ }^{7,8}$ and electron tunneling, ${ }^{9-11}$ respectively. The projected lifetime of holograms in the Mn-doped crystal at room temperature is approximately three years.

For holographic recording in congruently melting $\mathrm{LiNbO}_{3}$ by use of transmission geometry, the bulk photovoltaic current is dominant. The saturation

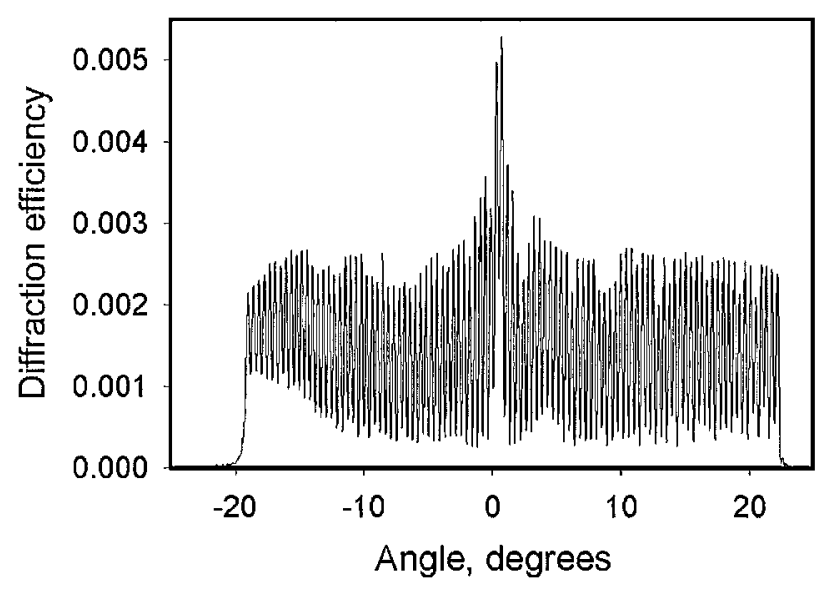

Fig. 2. Comb function of multiplexing 100 holograms in $\mathrm{LiNbO}_{3}: 0.2$-at. $\% \mathrm{Mn}$. The $M / \#$ calculated from this comb function is 5 .

Table 1. Summary of Oxidation States of the Mn-Doped $\mathrm{LiNbO}_{3}$

\begin{tabular}{|c|c|}
\hline $\begin{array}{c}\text { Oxidation } \\
\text { State }\end{array}$ & Thermal Treatment \\
\hline \multirow[t]{2}{*}{1} & Highly oxidized \\
\hline & $\begin{array}{l}\text { Starting with state } 6 \text {, in oxygen at } \\
930^{\circ} \mathrm{C} \text { for } 24 \mathrm{~h}\end{array}$ \\
\hline 2 & Starting with state 1 , in argon at $780^{\circ} \mathrm{C}$ for $1 \mathrm{~h}$ \\
\hline 3 & Starting with state 2 , in argon at $780^{\circ} \mathrm{C}$ for $3 \mathrm{~h}$ \\
\hline 4 & Starting with state 3 , in argon at $780^{\circ} \mathrm{C}$ for $4 \mathrm{~h}$ \\
\hline 5 & $\begin{array}{l}\text { Starting with state } 4 \text {, in argon at } \\
780^{\circ} \mathrm{C} \text { for } 11 \mathrm{~h}\end{array}$ \\
\hline 6 & $\begin{array}{l}\text { Highly reduced in vacuum at } 1000^{\circ} \mathrm{C} \text { for } 14 \mathrm{~h} \text {, } \\
\text { then in oxygen at } 925^{\circ} \mathrm{C} \text { for } 4 \mathrm{~h}\end{array}$ \\
\hline
\end{tabular}
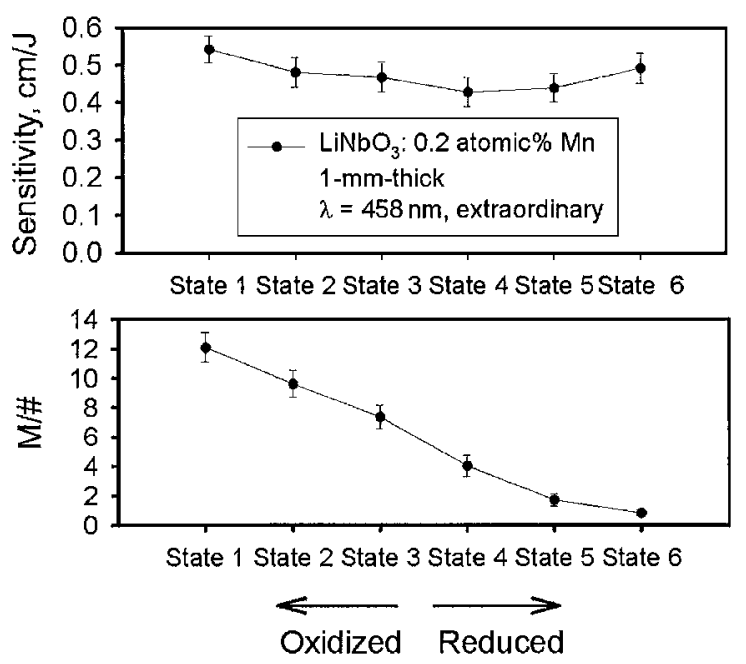

Fig. 3. Measured sensitivity and $M / \#$ versus oxidation state in 1-mm-thick $\mathrm{LiNbO}_{3}: 0.2$ at. \% Mn. 


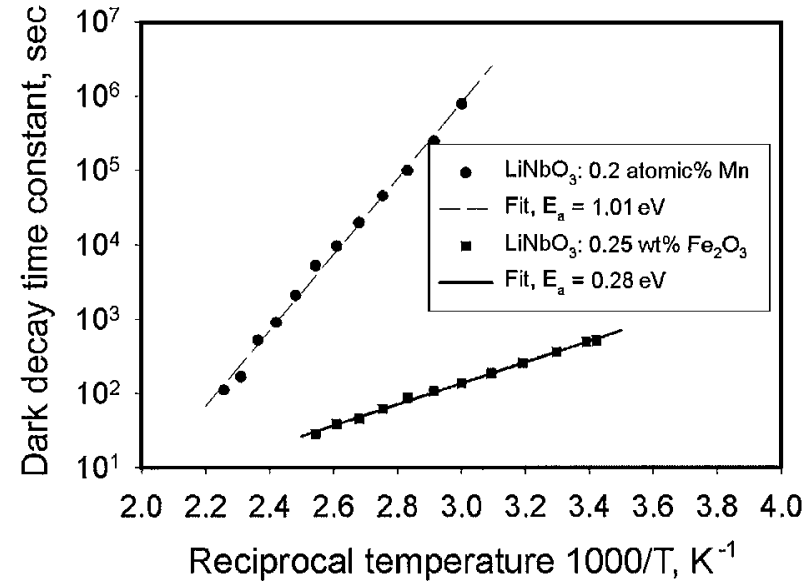

Fig. 4. Arrhenius plot of the dark decay time constants of nonfixed holograms stored in Mn-doped $\mathrm{LiNbO}_{3}(0.2$-at. \% $\mathrm{Mn})$, and Fe-doped $\mathrm{LiNbO}_{3}\left(0.25\right.$-wt.\% $\left.\mathrm{Fe}_{2} \mathrm{O}_{3}\right)$.

refractive-index change, $\Delta n_{s}$, is proportional to $\gamma$ and $C_{X^{3+}}$, where $\gamma$ is the recombination coefficient and $C_{X^{3+}}$ is the concentration of ionized donors. For $\mathrm{LiNbO}_{3}: \mathrm{Mn}$ crystals, the recombination coefficient $\gamma_{\mathrm{Mn}}$ is much larger than that of $\mathrm{LiNbO}_{3}: \mathrm{Fe}$ because the Mn center is deeper $\left(\gamma_{\mathrm{Mn}}=2.4 \times 10^{-13} \mathrm{~m}^{3} / \mathrm{s}\right.$ versus $\left.\gamma_{\mathrm{Fe}}=1.65 \times 10^{-14} \mathrm{~m}^{3} / \mathrm{s}\right){ }^{12} \quad$ Furthermore, the doping level $(0.2$ at. \%) is high. The large recombination coefficient, $\gamma_{\mathrm{Mn}}$, coupled with the high doping level in the $\mathrm{Mn}$-doped crystal makes the large $M / \#$ easily achievable.

One possible way to account for the lack of a trade-off between $M / \#$ and sensitivity in the $\mathrm{LiNbO}_{3}: \mathrm{Mn}$ crystal is by assuming that a large majority of the Mn traps are occupied by electrons. When we make this assumption, the sensitivity, which is proportional to the filled trap density, does not decrease when the $\mathrm{LiNbO}_{3}: \mathrm{Mn}$ crystal is oxidized and a small percentage change in the $\mathrm{Mn}^{2+}$ concentration takes place. However, the percentage change of $\mathrm{Mn}^{3+}$ is large, leading to an increase in $M / \#$ as the crystal is oxidized. Since we assume that most of the $\mathrm{Mn}$ traps are $\mathrm{Mn}^{2+}$, considering the doping level (0.2 at. \%), the sensitivity could be high.

Generally, both proton compensation and electron tunneling contribute to the dark decay in $\mathrm{LiNbO}_{3}$ crystals. But in $\mathrm{LiNbO}_{3}$ crystals with low doping levels, electron tunneling is very weak and the dark decay is dominated by proton compensation. In crystals with high doping levels, the dominant dark decay is electron tunneling. ${ }^{11}$ There are two possible reasons that the dark decay in the Mn-doped crystal is dominated by proton compensation. One possibility is that the actual doping level in the $\mathrm{Mn}$-doped crystal is much lower than the nominal one. In this case, the large $M$ /\# could be just the result of the large recombination coefficient, $\gamma_{\mathrm{Mn}}$, and the dark decay mechanism, which is dominated by proton compensation, could just be typical in $\mathrm{LiNbO}_{3}$ with low doping levels. The other possibility is that the actual doping is $\sim 0.2$ at. \%, and, since the Mn center is deeper than the Fe center, the electron-tunneling effect is still weak in the Mn-doped $\mathrm{LiNbO}_{3}$, and therefore the dark decay is dominated by proton compensation.

This effort was sponsored by the National Science Foundation (NSF), the Engineering Research Center for Neuromorphic Systems Engineering, and the Defense Advanced Research Projects Agency. The authors thank the NSF and the Deutscher Akademischer Austauschdienst for sponsoring the U.S.-German collaboration. We thank Ingo Nee for fruitful discussions. Y.-P. Yang's e-mail address is yunping@ sunoptics.caltech.edu.

\section{References}

1. H. J. Coufal, D. Psaltis, and G. T. Sincerbox, Holographic Data Storage (Springer, New York, 2000).

2. V. Leyva, G. A. Rakuljic, and B. O'Conner, Appl. Phys. Lett. 65, 1079 (1994).

3. R. Müller, M. T. Santos, L. Arizmendi, and J. M. Cabrera, J. Phys. D 27, 241 (1994).

4. S. Breer, H. Vogt, I. Nee, and K. Buse, Electron. Lett. 34, 2419 (1998).

5. K. Buse, A. Adibi, and D. Psaltis, Nature 393, 665 (1998).

6. F. Mok, G. Burr, and D. Psaltis, Opt. Lett. 21, 896 (1996).

7. D. L. Staebler and J. J. Amodei, Ferroelectrics 3, 107 (1972).

8. A. Yariv and S. Orlov, J. Opt. Soc. Am. B 13, 2513 (1996).

9. I. B. Barkan, A. V. Vorob'ev, and S. I. Marennikov, Sov. J. Quantum Electron. 9, 492 (1979).

10. I. Nee, M. Müller, K. Buse, and E. Krätzig, J. Appl. Phys. 88, 4282 (2000).

11. Y. Yang, I. Nee, K. Buse, and D. Psaltis, Appl. Phys. Lett. 78, 4076 (2001).

12. A. Adibi, K. Buse, and D. Psaltis, J. Opt. Soc. Am. B 18, 584 (2001). 